\title{
PRAÇAS E PARQUES - MICRORREGIÃO 08 DE PRESIDENTE PRUDENTE/SP
}

Brenda Norbiato Fedato; Joanne Rodrigues Damno da Costa; Mayara Pissutti Albano; Yeda Ruiz Maria.

Universidade do Oeste Paulista - UNOESTE. Curso de Arquitetura e Urbanismo, Presidente Prudente - SP. E-mail: yedarrm@hotmail.com

\section{RESUMO}

Os espaços públicos são áreas urbanas ao ar livre, destinadas à população em geral, e voltadas para prática de atividades ligadas ao lazer como o passeio, descanso e esportes. Essas áreas são de grande importância para sociedade tanto no aspecto social, como estético e até ambiental. 0 presente artigo tem como objetivo mapear e levantar as áreas referentes às praças e parques da microrregião 8 de Presidente Prudente - SP, identificar e mapear seus mobiliários, tanto no aspecto quantitativo como também qualitativo. E por fim, analisar as formas de uso e ocupação dessas áreas. A metodologia é baseada em levantamentos bibliográficos, pesquisas documentais e levantamentos físicos territoriais.

Palavras-chave: Espaços públicos; praças e parques; mobiliários urbanos; microrregião 8; Presidente Prudente-SP.

\section{SQUARES AND PARKS - MICROREGION 08 FROM PRESIDENTE PRUDENTE /SP}

\begin{abstract}
Public spaces are outdoor urban areas, intended for the general population, and focused on practice of activities related to leisure as walking, rest and sports. These areas are of great importance to society in both social and aesthetic and even environmental. This paper aims to map and raise the areas related to the squares and parks of the microregion 8 from Presidente Prudente - SP, identify and map its furniture, both in the quantitative aspect but also qualitative. And lastly, analyze the forms of use and occupation of these areas. The methodology is based on literature surveys, documentary research and territorial physical surveys.
\end{abstract}

Keywords: Public spaces; squares and parks; street furniture; microregion 8; Presidente Prudente $-\mathrm{SP}$. 


\section{INTRODUÇÃO}

O espaço urbano, segundo Matos (2010), é organizado em espaços públicos e privados, e embora haja prevalência do privativo, são as áreas públicas que melhor o definem. Essas áreas constituem o cenário para os acontecimentos da vida cotidiana, e servem como elemento principal de conexão na cidade, sendo formados por parques, praças, mirantes, calçadões etc (QUEIROGA, 2011).

De acordo com Santini (1993), a tipologia dos equipamentos de uma área de lazer deve ser voltada para o passeio, a descontração, jogos, atividades ao ar livre, esportes, espetáculos, encontros, vida social. Neste contexto compreende-se que as praças e parques são áreas públicas por excelência que devem garantir o direito ao lazer da população urbana, além de exercerem fundamental importância no âmbito higienista, pois estas quando adequadamente instaladas, garantem maior permeabilidade das águas pluviais no solo das cidades, diminuem os problemas que podem ser causados pelo escoamento das águas de chuva, bem como garantem a ventilação e promovem melhor conforto térmico ambiental à população.

A lei federal no 6.766/1979 apresenta diretrizes a serem seguidas, referentes ao parcelamento do solo urbano, prevendo a presença de áreas de circulação, espaços livres e implantação de equipamentos urbanos e comunitários (art. 4). No município de Presidente Prudente-SP o Plano Diretor (lei no154/2008) apresenta os requisitos mínimos referentes às áreas públicas nos loteamentos urbanos.

A presente pesquisa tem como foco analisar as praças e parques da microrregião 08 , localizada na porção sul da cidade de Presidente Prudente-SP, composta pelos seguintes bairros: Chácara do Macuco I, Chácara do Macuco II, Cond. Residencial Jardins de Anahy, Residencial Florenza, Parque Residencial Nosaki, Residencial Beatriz, Jardim Satélite, Jardim Alto da Boa Vista, Parque Higienópolis, Bosque Itajú, Jardim Rio 400, Residencial Século XXI, Vila Maria, Vila Nova Prudente, Residencial Damha, Residencial Damha I, Residencial Damha II, Vilage Damha, Residencial Golden Vilage, Residencial Quinta das Flores (figura 1).

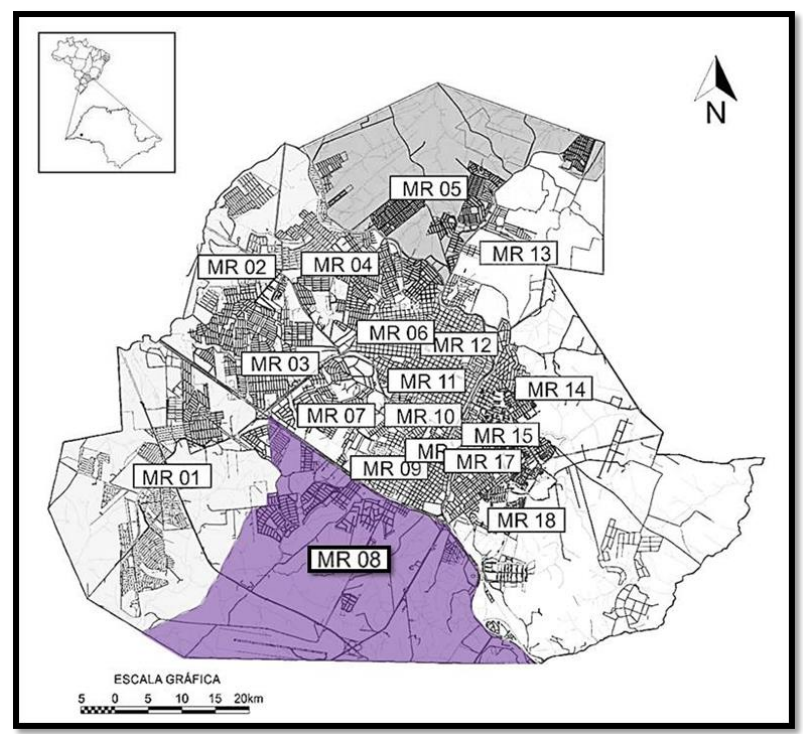

Figura 01. Microrregião 08 na cidade de Presidente Prudente-SP Fonte: Autoras, 2016.

Primeiramente foi verificado sua função atual junto à legislação municipal, apontando a quantidade e qualidade dos mobiliários presentes nessas áreas e por fim identificando as formas de uso e ocupação dessas praças e parques. Para tanto fez-se necessário levantamentos bibliográficos, pesquisas documentais e levantamentos físicos territoriais urbanísticos. 


\section{LEVANTAMENTO DAS ÁREAS PÚBLICAS DE LAZER DA MICRORREGIÃO 08 COM BASE NO PLANO DIRETOR MUNICIPAL}

Os levantamentos (tabela 1) feitos mostram que a grande maioria dos bairros apresentam o mínimo de $10 \%$ (dez por cento) da área loteável destinada ao lazer.

Tabela 01. Levantamento das áreas públicas de lazer da Microrregião 08.

\begin{tabular}{|c|c|c|c|c|}
\hline bairro & área total loteada $\left(\mathrm{m}^{2}\right)$ & área total lazer $\left(\mathrm{m}^{2}\right)$ & $\begin{array}{l}\text { atende à } \\
\text { legislação }\end{array}$ & $\begin{array}{c}\text { não atende à } \\
\text { legislação }\end{array}$ \\
\hline bosque itajú & $37.538,00$ & $3.753,80$ & $x$ & \\
\hline chácara do macuco I & $70.000,00$ & $7.039,65$ & $x$ & \\
\hline chácara do macuco II & $91.742,80$ & $9.429,45$ & $x$ & \\
\hline $\begin{array}{l}\text { cond. residencial jardins de } \\
\text { anahy }\end{array}$ & - & - & - & - \\
\hline jardim alto da boa vista & $209.193,00$ & $21.534,00$ & $x$ & \\
\hline jardim rio 400 & $149.120,00$ & $16.687,00$ & $x$ & \\
\hline jardim satélite & $34.275,73$ & $3.643,49$ & $x$ & \\
\hline parque higienópolis & $309.157,00$ & $32.294,00$ & $x$ & \\
\hline parque residencial nosaki & $146.724,25$ & $14.732,62$ & $x$ & \\
\hline residencial beatriz & $46.981,96$ & $5.514,45$ & $x$ & \\
\hline parque residencial damha I & $620.367,29$ & $95.578,76$ & $x$ & \\
\hline parque residencial damha II & $430.943,07$ & $63.365,33$ & $x$ & \\
\hline parque residencial damha III & $362.465,50$ & $50.362,00$ & $x$ & \\
\hline residencial florenza & $285.452,12$ & $29.527,17$ & $x$ & \\
\hline residencial golden village & $83.195,80$ & $8.472,19$ & $x$ & \\
\hline residencial quinta das flores & $131.432,16$ & $13.442,62$ & $x$ & \\
\hline residencial séc. xxi & $104.800,00$ & $10.490,04$ & $x$ & \\
\hline vila mariana & $26.503,14$ & - & & $x$ \\
\hline vila nova prudente & $96.123,06$ & $1.442,51$ & $x$ & \\
\hline village damha & $159.595,00$ & $20.072,50$ & $x$ & \\
\hline \multicolumn{5}{|c|}{$\begin{array}{l}\text { OBS: A prefeitura de Presidente Prudente não possui os dados referentes ao parcelamento do Condomínio } \\
\text { Residencial Jardins de Anahy. }\end{array}$} \\
\hline
\end{tabular}

Fonte: Autoras, 2016.

A única exceção é o bairro Vila Mariana, que não apresenta área destinada ao lazer tanto em seu projeto de parcelamento aprovado bem como em sua situação física atual.

Vale pontuar ainda que microrregião 08 tem grande concentração de condomínios fechados e esses espaços são de acesso restrito, não sendo possível as análises in loco.

A tabela abaixo apresenta se existe o cumprimento da função original das áreas ou se desempenham outra função, a quantidade e qualidade dos mobiliários, se há presença de vegetação arbórea, iluminação e uso. 
Tabela 02. Situação atual das áreas públicas de lazer da microrregião 08.

\begin{tabular}{|c|c|c|c|c|c|c|c|}
\hline praça por bairro & $\begin{array}{l}\text { segue } \\
\text { função } \\
\text { original }\end{array}$ & $\begin{array}{l}\text { outra } \\
\text { função }\end{array}$ & $\begin{array}{l}\text { quantidade } \\
\text { mobiliário }\end{array}$ & $\begin{array}{l}\text { qualidade } \\
\text { mobiliário }\end{array}$ & $\begin{array}{l}\text { vegetação } \\
\text { arbórea }\end{array}$ & iluminação & uso \\
\hline bosque itajú & $x$ & & 10 & regular & $x$ & $x$ & \\
\hline chácara do macuco I & & $x$ & & & $x$ & & \\
\hline chácara do macuco II & & $x$ & & & $x$ & & \\
\hline jardim alto da boa vista praça I & $x$ & $x$ & 47 & regular & $x$ & $x$ & $\mathrm{x}$ \\
\hline $\begin{array}{c}\text { jardim alto da boa vista praça } \\
\text { II }\end{array}$ & & $x$ & & & $\mathrm{x}$ & & \\
\hline jardim rio 400 - praça I & & $x$ & & & $x$ & & \\
\hline jardim rio 400 - praça II & $x$ & & 15 & bom & $x$ & $x$ & \\
\hline jardim satélite & & $x$ & & & & & \\
\hline parque higienópolis praça I & $x$ & & 26 & regular & $x$ & $x$ & \\
\hline parque higienópolis praça II & $x$ & & 33 & regular & $x$ & $x$ & \\
\hline $\begin{array}{c}\text { parque residêncial nosaki } \\
\text { praça I }\end{array}$ & $x$ & & 25 & bom & $x$ & & $\mathrm{x}$ \\
\hline $\begin{array}{c}\text { parque residêncial nosaki } \\
\text { praça II }\end{array}$ & $x$ & & 6 & regular & $x$ & & $\mathrm{x}$ \\
\hline residencial florenza praça I & & $x$ & & & & & \\
\hline residencial florenza praça II & $x$ & & 22 & regular & $x$ & & \\
\hline residencial florenza praça III & & $x$ & 1 & regular & $x$ & & \\
\hline residencial florenza praça IV & & $x$ & 18 & regular & & $x$ & $\mathrm{x}$ \\
\hline residencial sec. XXI & & $x$ & & & & & \\
\hline vila nova prudente praça I & $x$ & & 15 & ruim & $x$ & $x$ & $x$ \\
\hline vila nova prudente praça II & $x$ & & 28 & regular & $x$ & $x$ & $x$ \\
\hline
\end{tabular}

Fonte: autoras, 2016.

\section{Análise de usos}

Bosque Itajú - A área pública de lazer fica localizada em uma rua sem saída, onde existe um menor fluxo de automóveis e pedestres. Apresenta como mobiliário apenas um playground infantil e bancos de concreto, que ficam concentrados em uma das extremidades da área. A vegetação arbórea é pouca e concentrada com presença de grama em toda extensão. Com relação ao uso, constatou-se que não há um uso frequente do local, podendo ter relação direta com o modo como a área se encontra isolada de seu entorno.

Chácara do Macuco I e II - A Chacara Macuco I apresenta área pública destinada ao lazer de acordo com a legislação vigente, porém é um grande vazio urbano sem uso. Já a Chacara Macuco II não estruturou sua área de pública de lazer, o que resultou em um grande vazio urbano com pouca vegetação.

Jardim Alto da Boa Vista - No lote "G" constatou-se que parte de sua área teve alteração de função e foi cedida para construção de uma unidade dos Correios com área de $4.890,57 \mathrm{~m}^{2}$ eos outros 16643,43 $\mathrm{m}^{2}$ remanescentes desta área, não foram beneficiados com nenhum projeto urbanístico de praça ou parque. A quadra " $\mathrm{H}$ " teve preservada sua função de Lazer e possui área de $13.224 \mathrm{~m}^{2}$, conta com 02 mini-campos de futebol gramados, sendo 1 fechado por alambrado e o outro sem barreiras físicas, possui também academia para 3a idade e alguns mobiliários executados em concreto como bancos, mesas, já em parte, danificados, mas apesar da pouca 
infra-estrutura e baixa manutenção, a praça é utilizada por crianças e adolescentes da região para brincadeiras e partidas de futebol, recebe em passeios vespertinos as crianças especiais da Lúmen Et Fides, o lote também conta com ponto de ônibus e serve como um lugar de espera para os usuários do transporte coletivo, em sua esquina foi implantado um trailer de lanche que funciona no horário noturno, um comércio particular que atende os moradores do entorno.

Jardim Rio 400 - Apresenta duas áreas públicas destinadas ao lazer. A primeira área se encontra vazia com vegetação rasteira densa e sem presença de mobiliário. A segunda área apresenta como mobiliário uma academia da terceira idade e um campo de futebol, com pouca vegetação arbórea. A iluminação no local não é suficiente, com a presença de apenas um poste de iluminação que fica localizado junto à academia de terceira idade. A área não apresenta uso frequente.

Jardim Satélite - Na área pública destinada ao lazer, indicada no projeto de loteamento, constatou-se a presença do prédio sede da União de Pessoas com Deficiência - UNIPODE, inviabilizando o cumprimento de sua função.

Parque Higienópolis - O bairro apresenta duas áreas públicas de lazer. A primeira área é formada em sua grande parte por um bosque e apresenta duas pequenas áreas com playground infantil e academia da terceira idade, com boa arborização e iluminação, sem uso frequente. A segunda área apresenta campo de futebol, playground infantil, um depósito de alvenaria, bancos de concreto e barras para exercícios físicos. Apresenta também alguns mobiliários que parecem ser colocados pelos moradores como um banco em madeira com pergolado, vasos com plantas e um conjunto de mesa e cadeira de ferro. Apresenta boa arborização e iluminação, mas também não existe uso frequente do local.

Residencial Nosaki - Espaço subutilizado, apenas constatou-se o uso da academia por crianças, estas foram encontradas no local apenas durante o dia. Todo o restante do espaço bem como o campo de futebol e playground descoberto não é utilizado, e no período noturno a praça com péssima iluminação com grandes áreas escuras ou na penumbra, o que promove a sensação de insegurança o que inviabiliza o uso neste período.

Residencial Florenza - Espaço possui uma pequena praça que recebeu intervenção de moradores, porém não foi constatado uso durante as visitas, embora o local encontra-se conservado. Ainda neste bairro existe um grande espaço descampado com poucos mobiliários, mas com grande uso por parte dos moradores, foi constatada a intensa presença de mães ou pais com crianças sejam no período matutino ou noturno, todos deste perfil utilizavam à academia, mas com fins recreativos e não com o propósito original do mobiliário que seriam exercícios físicos.

Residencial Séc. XXI - O bairro não se encontra consolidado, sendo apenas uma área vazia, sem presença de árvores e com pontos de concentração de entulho.

Vila Nova Prudente - Nos projetos de loteamentos não consta a existência de áreas de lazer, entretanto as vistas in loco ficou clara a existência de duas praças. A primeira praça apresenta como mobiliário playground infantil, academia da terceira idade, rede de internet sem fio e bancos de concreto, apresenta boa arborização e iluminação concentrada nas extremidades deixando o centro da praça escuro. Tem um bom uso, principalmente no final da tarde, com crianças brincando e pessoas conversando. A segunda praça fica localizada entre os lotes de uma das quadras, apresenta playground infantil (sem conservação), campo de areia e bancos de concreto com boa arborização e iluminação. $O$ uso desse local também é maior no final da tarde quando crianças usam o campo e os moradores conversam e transitam pela área.

\section{CONSIDERAÇÕES FINAIS}

Embora exista o Plano Diretor Municipal, garantindo espaços destinados ao lazer nos loteamentos da cidade, não há garantia de que sua função não será alterada.

Foram encontradas áreas de lazer criadas pelos próprios moradores onde a população buscou por iniciativa própria intervir nestes espaços, talvez por falta de conhecimento legal de como exigir tais direitos frente ao poder público. 
Outra importante observação está relacionada às condições sócio-econômicas de cada localidade, bairros que alojam pessoas menos favorecidas, necessitam mais da qualificação dos espaços públicos, enquanto que sistemas residenciais como os condomínios fechados tendem a segregar as áreas públicas, pois promovem por meio de investimentos privados centros de recreação e lazer exclusivos aos seus moradores.

A respeito dos mobiliários, fica constatada a preferência dos populares pelas academias da 3a idade, não por sua função original, mas por certamente serem a intervenção mais recente e conservada destes locais, logo a estas foram atribuídas novas funções como a recreação, o sentar, contemplar, além de servir para as atividades físicas de alguns moradores.

É possível observar que a maioria das áreas não apresenta uso regular, seja por falta de qualidade, pela localização ou até por falta de interesse da população. Diante do exposto constata-se que os espaços destinados às praças perderam seu prestígio como espaço de sociabilidade, encontro e lazer, em função da falta de qualificação adequada dos mesmos, mas ainda exercem grande papel como área livre, espaço de circulação e em alguns casos como áreas verdes.

\section{REFERÊNCIAS}

BRASIL, Lei n. 6.766 de 19 de dezembro de 1979. Dispõe sobre parcelamento do solo e dá outras providencias.

MATOS, Fátima Loureiro, Espaços públicos e qualidade de vida das cidades - O caso da cidade Porto. Observatorium: Revista eletrônica de geografia v.2, n.4, p.17-33, jul. 2010.

PRESIDENTE PRUDENTE. Lei n. 154 de 10 de janeiro de 2008. Dispõe sobre o parcelamento do solo para fins urbanos e dá outras providências.

QUEIROGA, Eugênio Fernandes, Sistemas de espaços livres e esfera pública em metrópoles brasileiras. Resgate- vol. XIX, NO 21 - jan./jun. 2011.

SANTINI, Rita de Cássia Giraldi. Dimensões do lazer e da recreação: questões espaciais, sociais e psicológicas. São Paulo. Angelotti, 1993. 